\title{
The Presynaptic Choline Transporter Imposes Limits on Sustained Cortical Acetylcholine Release and Attention
}

\author{
Vinay Parikh, ${ }^{1}$ Megan St. Peters, ${ }^{2}$ Randy D. Blakely, ${ }^{3}$ and Martin Sarter ${ }^{2}$ \\ ${ }^{1}$ Department of Psychology and Neuroscience Program, Temple University, Philadelphia, Pennsylvania 19122, ${ }^{2}$ Department of Psychology, University of \\ Michigan, Ann Arbor, Michigan 48103, and ${ }^{3}$ Departments of Pharmacology and Psychiatry, Vanderbilt University School of Medicine, Nashville, Tennessee \\ 37232-8548
}

Functional variation in the gene encoding the presynaptic choline transporter (CHT) has been linked to attention-deficit/hyperactivity disorder. Here, we report that a heterozygous deletion in the $\mathrm{CHT}$ gene in mice $\left(\mathrm{CHT}^{+/-}\right)$limits the capacity of cholinergic neurons to sustain acetylcholine $(\mathrm{ACh})$ release and attentional performance. Cortical microdialysis and amperometric methods revealed that, whereas wild-type and $\mathrm{CHT}^{+/-}$animals support equivalent basal ACh release and choline clearance, $\mathrm{CHT}^{+/-}$animals exhibit a significant inability to elevate extracellular ACh following basal forebrain stimulation, in parallel with a diminished choline clearance capacity following cessation of stimulation. Consistent with these findings, the density of CHTs in cortical synaptosomal plasma membraneenriched fractions from unstimulated $\mathrm{CHT}^{+/-}$animals matched those observed in wild-type animals despite reductions in $\mathrm{CHT}$ levels in total extracts, achieved via a redistribution of $\mathrm{CHT}$ from vesicle pools. As a consequence, in $\mathrm{CHT}^{+/-}$animals, basal forebrain stimulation was unable to mobilize wild-type quantities of CHT to the plasma membrane. In behavioral studies, $\mathrm{CHT}^{+1-}$ mice were impaired in performing a sustained attention task known to depend on cortical cholinergic activity. In wild-type mice, but not $\mathrm{CHT}^{+/-}$mice, $^{-}$ attentional performance increased the density of CHTs in the synaptosomal membrane in the right frontal cortex. Basal CHT levels in vesicle-enriched membranes predicted the degree of $\mathrm{CHT}$ mobilization as well as individual variations in performance on the sustained attention task. Our findings demonstrate biochemical and physiological alterations that underlie cognitive impairments associated with genetically imposed reductions in choline uptake capacity.

\section{Introduction}

Basal forebrain (BF) cholinergic projections to cortex are necessary for attentional performance (Hasselmo and Sarter, 2011). Abnormalities in the integrity, regulation, and capacity of cholinergic neurons contribute to the cognitive symptoms of neuropsychiatric and neurodegenerative disorders (Mesulam, 2004; Sarter et al., 2012). However, animal models used to investigate the impact of cholinergic dysregulation on cognitive functions have largely remained restricted to cholinergic lesions and pharmacological manipulations.

The sodium-dependent, high-affinity choline transporter (CHT) is expressed selectively in cholinergic neurons (Misawa et al., 2001; Kus et al., 2003). CHT transports choline from the extracellular space into presynaptic terminals, a step essential for the synthesis of acetylcholine (ACh) (Yamamura and Snyder, 1972; Simon et al., 1976). Early studies using the competitive

Received 0ct. 24, 2012; revised Nov. 28, 2012; accepted Dec. 8, 2012.

Author contributions: V.P. and M.S. designed research; V.P. and M.S.P. performed research; V.P. and M.S.P. analyzed data; V.P., R.D.B., and M.S. wrote the paper.

This research was supported by Public Health Service Grants MH086530 (M.S., V.P., R.D.B.) and MH073159 (R.D.B.). We thank Damon Young (now at Pfizer) for assistance with the microdialysis experiments. We also thank Ali Cheema, Kevin Taylor, and Avery Zucco for assistance with genotyping, subcellular fractionation, and immunoblot analyses; and Sarah Whitaker and Jane Wright for technical assistance.

Correspondence should be addressed to Martin Sarter, University of Michigan, 4030 East Hall, 530 Church Street, Ann Arbor, MI 48109. E-mail: msarter@umich.edu.

DOI:10.1523/JNEUROSCI.4993-12.2013

Copyright $\odot 2013$ the authors $\quad 0270-6474 / 13 / 332326-12 \$ 15.00 / 0$
CHT antagonist hemicholinium-3 (HC-3) indicated the necessity of CHT-mediated choline transport for cholinergic neurotransmission and brain function (Robinson and Green, 1980; Manaker et al., 1986; Saltarelli et al., 1987), findings reinforced by the presence of hereditary motorneuropathy in humans bearing a heterozygous deletion of CHT sequences (Barwick et al., 2012) and the early neonatal lethality of CHT KO mice due to paralysis and asphyxiation (Ferguson et al., 2004).

Common genetic variation in the human CHT gene (SLC5A7), including a coding variant (IIe89Val) that produces an $\sim 50 \%$ decrease of wild-type choline uptake capacity in vitro, has been associated with disorders with cognitive deficits including major depression and attention-deficit/hyperactivity disorder (ADHD) (Hahn et al., 2008; English et al., 2009). Additionally, both the amyloid precursor protein and amyloid- $\beta$ physically associate with $\mathrm{CHT}$ and impact its targeting to presynaptic membranes (Bales et al., 2006; Wang et al., 2007), suggesting that CHT may participate in the elaboration of deficits in basal forebrain cholinergic signaling in Alzheimer's disease (Auld et al., 2002; Sarter and Parikh, 2005).

Except for local and transient increases in choline levels as a result of ACh hydrolysis, reaching $\sim 15 \mu \mathrm{M}$, extracellular levels of choline are stable at 3-5 $\mu \mathrm{M}$ in the rat brain (Parikh and Sarter, 2006). The majority of CHTs at steady state are located on synaptic vesicles (Ferguson et al., 2003). Depolarization of cholinergic terminals increases the density of CHTs in synaptosomal plasma membrane in a $\mathrm{Ca}^{2+}$ and SNARE-dependent mecha- 
nisms, thereby increasing choline uptake into terminals (Ferguson et al., 2003; Ferguson and Blakely, 2004). CHTs can be efficiently recycled to intracellular vesicles via clathrin-mediated (Ribeiro et al., 2003, 2005), dynamin-dependent (Ferguson and Blakely, 2004) endocytosis, dictated by sequences of the transporter's cytoplasmic C terminus (Ribeiro et al., 2005; Ruggiero et al., 2012). Intracellular signaling pathways appear to be able to modulate choline uptake and/or CHT synaptic membrane density, suggesting that CHT is under tight regulation to control cholinergic signaling (Saltarelli et al., 1990; Gates et al., 2004; Pinthong et al., 2008).

Here, we determined the impact of the constitutive loss of $\mathrm{CHT}$ function on the capacity to sustain increases in cholinergic neurotransmission and related behavioral/cognitive performance. Together, our findings indicate that enhanced CHT surface expression is critical for the wide dynamic range of cholinergic signaling needed to support demanding cognitive tasks, and that CHT heterozygous mice may model effects of constitutive impairment of CHT function in humans.

\section{Materials and Methods}

Animals and genotyping. $\mathrm{CHT}$ heterozygous $\left(\mathrm{CHT}^{+/-}\right)$mice were originally generated at the Vanderbilt University Medical Center and maintained on a C57BL/6J genetic background for over seven generations (Ferguson et al., 2004; Bazalakova et al., 2007). Male $\mathrm{CHT}^{+/-}$breeder mice were shipped to the University of Michigan and backcrossed for three additional generations to obtain wild-type $\left(\mathrm{CHT}^{+/+}\right)$and heterozygous mutants $\left(\mathrm{CHT}^{-/-}\right.$animals die at birth). Animals were individually housed in a temperature-controlled $\left(23^{\circ} \mathrm{C}\right)$ and humiditycontrolled (45\%) environment with a $12 \mathrm{~h}$ light/dark cycle (lights on at 7:00 A.M.). Mice were genotyped by extracting genomic DNA from tail biopsies; DNA was subjected to PCR using oligonucleotide primers that amplifies a 841 bp product in $\mathrm{CHT}^{+/+}$mice and both 401 and $841 \mathrm{bp}$ products in $\mathrm{CHT}^{+/-}$mice (Ferguson et al., 2004) (Fig. 1). Following weaning, animals were individually housed and given food and water ad libitum. Adult mice of either sex weighing 20-25 g at the beginning of the experiments were used. All procedures were conducted in adherence with protocols approved by the University Committee on Use and Care of Animals.

Stimulation of basal forebrain. Mice were anesthetized with urethane $(1.25-1.5 \mathrm{~g} / \mathrm{kg}$, i.p) and placed in a stereotaxic frame. A concentric bipolar electrode (FHC) was lowered into the right basal forebrain (nucleus basalis of Meynert/substantia innominata region) to electrically stimulate cholinergic neurons by applying $1 \mathrm{~Hz}$ square pulse $(100 \mu \mathrm{A})$ trains of $500 \mathrm{~ms}$ for $20 \mathrm{~min}$ (Fig. 1a) using an isolated pulse stimulator (Model 2100; A-M Systems). Control animals were prepared in a similar way, but stimulation pulses were not applied (BF-sham). Animals were decapitated 10 or 90 min following stimulation of BF (BF-stim), and right frontal cortex was isolated for determining CHT densities (see below for immunoblotting methods). Prefrontal cortices from two animals were pooled to obtain a sufficient yield in the subcellular fractions. Separate groups of animals were used to determine the effects of BF-stim on the capacity of cholinergic terminals to release ACh and to clear exogenous choline (see below).

In vivo microdialysis. Extracellular levels of ACh under resting conditions and during BF-stim were determined using microdialysis in anesthetized $\mathrm{CHT}^{+/+}$and $\mathrm{CHT}^{+/-}$mice. Microdialysis probes with $2.0 \mathrm{~mm}$ membrane tips (CMA) were inserted into the medial PFC. Simultaneously, a bipolar electrode was lowered into the BF of ipsilateral hemisphere for electrical stimulation. Probes were perfused at a rate of 2.0 $\mu \mathrm{l} / \mathrm{min}$ with artificial CSF $(126.5 \mathrm{~mm} \mathrm{NaCl}, 27.5 \mathrm{~mm} \mathrm{NaHCO}, 2.4 \mathrm{KCl}$ mM, $0.5 \mathrm{~mm} \mathrm{NA}_{2} \mathrm{SO}_{4}, 0.5 \mathrm{~mm} \mathrm{KH}_{2} \mathrm{PO}_{4}, 1.2 \mathrm{~mm} \mathrm{CaCl}_{2}, 0.8 \mathrm{mM} \mathrm{MgCl}_{2}, 5.0$ $\mathrm{mm}$ glucose; $\mathrm{pH} 6.9 \pm 0.1)$ containing neostigmine $(10 \mu \mathrm{M})$. Following a $2 \mathrm{~h}$ discard period to allow ACh levels stabilize, four $10 \mathrm{~min}$ dialysates were collected to determine basal extracellular cortical ACh concentrations. Immediately after the fourth dialysate collection, BF-stim was initiated (see above). Dialysates were continuously collected during BF- stim $(20 \mathrm{~min})$ and the $50 \mathrm{~min}$ poststimulation period. ACh levels in the dialysates were determined by HPLC/electrochemical detection as described previously (Parikh et al., 2006). For the determination of basal ACh concentrations, absolute ACh values were corrected for individual probe recovery rate $(6-10 \%)$. To compare the effect of BF-stim on cortical ACh release between the two genotypes, release data were expressed as the percentage of basal release.

Amperometric recordings. Ceramic-based, multisite microelectrodes featuring four rectangular $(15 \times 333 \mu \mathrm{m})$ Platinum $(\mathrm{Pt})$ recording sites arranged in side-by-side pairs (Quanteon) were used for in vivo amperometric recording of choline signals as described previously (Parikh et al., 2004, 2008, 2010; Parikh and Sarter, 2006).

Microelectrodes were coated with choline-oxidase (ChOase) and calibrated in vitro. Calibrated electrodes that met calibration criteria were subsequently used for in vivo recordings. Briefly, ChOase (Sigma) was cross-linked with the BSA-glutaraldehyde mixture and immobilized onto the bottom pair of recording sites. The two top recording sites were coated only with BSA/glutaraldehyde alone and served to record background activity. Before calibration, metaphenylenediamine ( $m$-PD) was electropolymerized on the microelectrode to enhance selectivity for detecting choline by preventing access of electroactive interferents, including ascorbic acid (AA) and catecholamines, to the platinum recording sites. The $m$-PD-plated, enzyme-coated microelectrodes were soaked in 0.05 м PBS for $30 \mathrm{~min}$ before calibration. Calibrations were performed using fixed potential amperometry by applying a constant voltage of $+0.7 \mathrm{~V}$ versus $\mathrm{Ag} / \mathrm{AgCl}$ reference electrode (Bioanalytical Systems) in a beaker containing a stirred solution of $0.05 \mathrm{M}$ PBS $(40 \mathrm{ml})$ maintained at $37^{\circ} \mathrm{C}$ using a FAST-16 electrochemical system (Quanteon). Amperometric currents were digitized at a frequency of $5 \mathrm{~Hz}$. After achieving a stable baseline current, aliquots of stock solutions of AA ( $20 \mathrm{~mm})$, choline (20 $\mathrm{mM})$, and DA ( $2 \mathrm{~mm}$ ) were added to the calibration beaker such that the final concentrations were $250 \mu \mathrm{M} \mathrm{AA} ; 20,40,60$, and $80 \mu \mathrm{M}$ choline; and $2 \mu \mathrm{M}$ DA. The slope (sensitivity), limit of detection (LOD) and linearity $\left(R^{2}\right)$ for choline, as well as selectivity ratio for AA, were calculated for individual recording sites. To be used in subsequent in vivo experiments, electrodes were required to meet the following criteria: $>3 \mathrm{pA} / \mu \mathrm{M}$ sensitivity for detecting choline on enzyme-coated channels, with a background current of $<300 \mathrm{pA}$ on all recording sites; LOD $<400 \mathrm{~nm}$ choline; ratio of selectivity for choline and $\mathrm{AA},>80: 1$; detection of increasing analyte concentrations $(20-80 \mu \mathrm{M})$ on enzyme-coated platinum recording sites, $R^{2}>0.98$; and negligible changes in current on all recording channels after DA addition $(<3 \mathrm{pA})$.

Urethane-anesthetized mice were placed in a stereotaxic frame, and body temperature was maintained at $37^{\circ} \mathrm{C}$ using an isothermal pad. Single-barrel glass capillaries $(1.0 \times 0.58 \mathrm{~mm}, 6$ inches; A-M Systems $)$ were pulled using a micropipette puller (Model 51210, Stoelting) and then bumped until the diameter of the inner tip was $\sim 15 \mu \mathrm{m}$. The micropipette was attached to the microelectrode with the tip placed between the lower and upper pairs of recording sites, at a distance of $\sim 50$ $\mu \mathrm{m}$ from the electrode surface. A silver wire reference electrode was implanted at a remote site on the brain. The microelectrode/micropipette assembly was lowered into the right medial PFC (AP: $+1.9 \mathrm{~mm}$, ML: $-0.5 \mathrm{~mm}$, measured from bregma; DV: $-2.0 \mathrm{~mm}$, from dura) using a microdrive (MO-10, Narishige International). Additionally, electrical stimulation electrode (see above) was implanted into the BF region of the ipsilateral hemisphere to determine the consequences of BF-stim on depolarization-evoked ACh release and in vivo CHT capacity. Amperometric recordings were made at a frequency of either 1 or $10 \mathrm{~Hz}$, and data were digitized using a FAST-16 recording system (Quanteon). Experiments began following stabilization of the baseline current for $60 \mathrm{~min}$. Drug solutions were pressure ejected from the micropipettes either 10 or 90 min following BF-stim. To avoid any potentially confounding effects of tissue damage due to pressure ejection on choline signal amplitudes and kinetics, effects at 10 and 90 min after BF-stim were assessed in separate groups of mice. Control animals were prepared for recordings in a similar way except that electrical pulses were not applied. The effects of pressure ejections of $\mathrm{KCl}(70 \mathrm{~mm} ; 50 \mathrm{nl})$ on cholinergic signal amplitudes were assessed in $\mathrm{CHT}^{+/+}$and $\mathrm{CHT}^{+/-}$mice. Such potassium-evoked choline signals were repeatedly shown to indicate choline generated by 
a

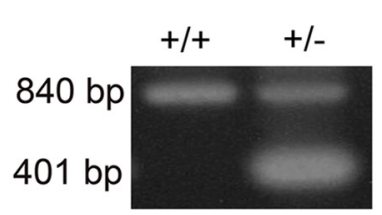

b

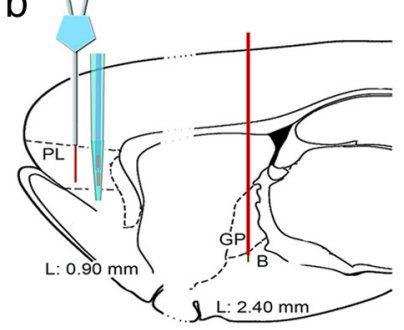

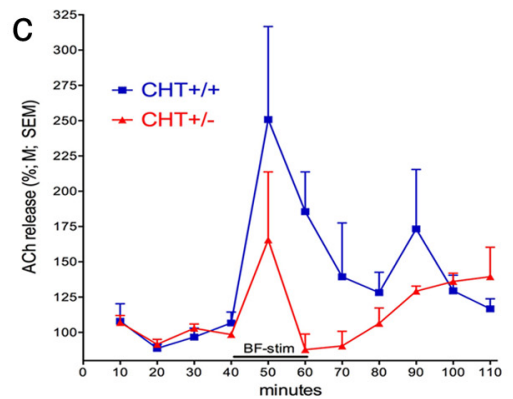

d

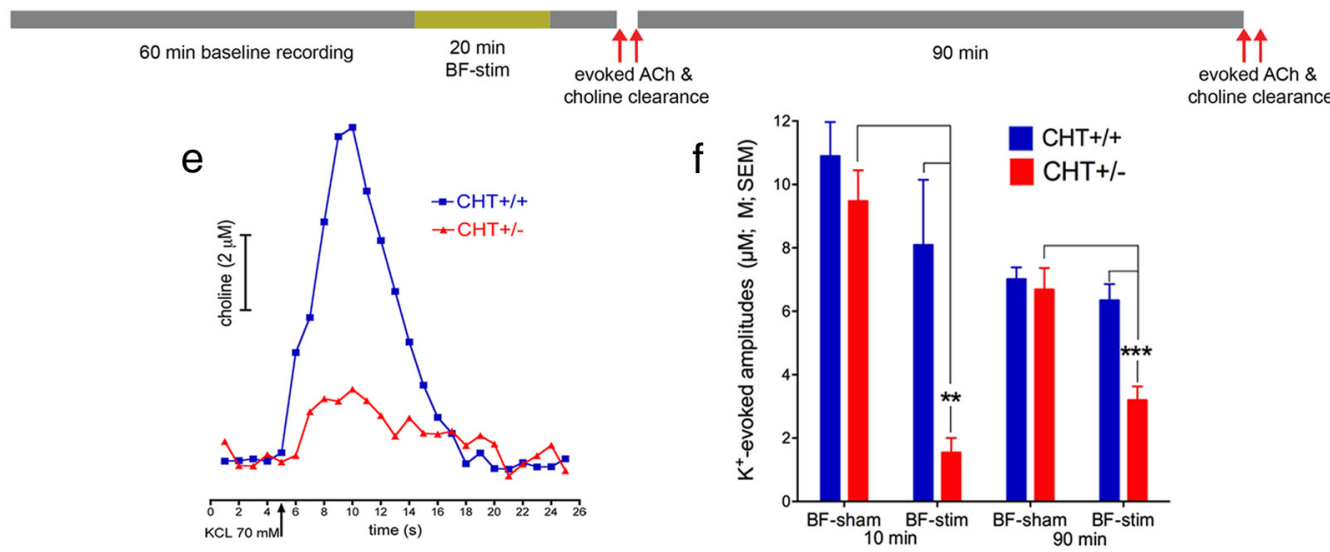

g
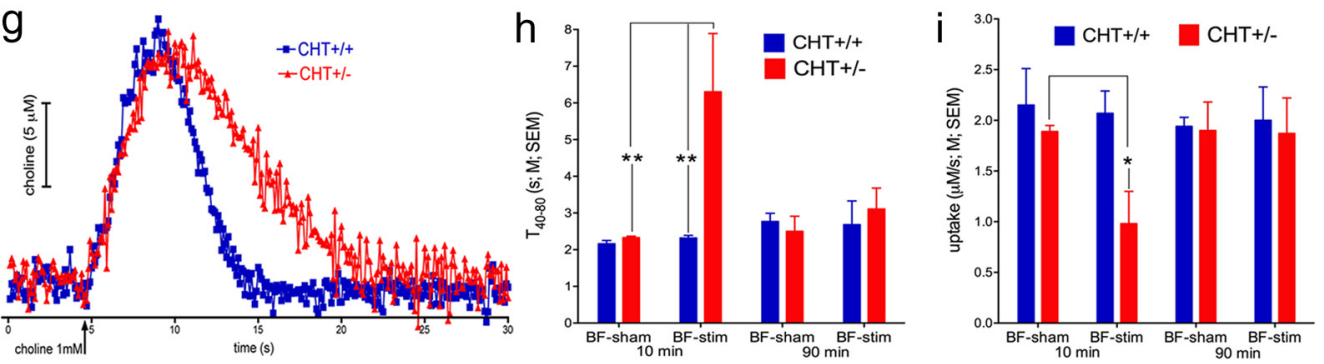

Figure 1. ACh release and choline clearance capacity at baseline and after electrical BF-stim. $\boldsymbol{a}$ exemplifies the PCR-based genotyping strategy (Ferguson et al., 2004) that revealed two gene products in $\mathrm{CHT}^{+/-}$mice, compared with the single product of $840 \mathrm{bp}$ in wild-type mice. $\boldsymbol{b}$, Lateral brain section (note the different lateral levels of the more anterior and more posterior regions) illustrating the placement and approximate dimensions of the bipolar stimulation electrode in the region of the magnocellular cholinergic neurons of the nucleus basalis of Meynert (B) and the cholinergic neurons of the more ventral substantial innominata [globus pallidus (GP)], the microdialysis probe with the active membrane placed in the middle layers of the prelimbic cortex (PL), and the four Pt sites on the ceramic electrode likewise placed in the middle layers of the PL. Choline oxidase was immobilized onto two of the four Pt sites while the other two served for recording currents evoked by electroactive interferents (see In vitro calibration in Materials and Methods). c, Prefrontal ACh release, measured by using microdialysis before, during, and after BF-stim in wild-type ( $n=$ 5) and $\mathrm{CHT}^{+/-}$mice $(n=4)$. ACh release in $\mathrm{CHT}^{+/-}$mice was attenuated during and after BF-stim (main effect of genotype; see Results for ANOVA). $d$ illustrates the timeline for electrochemical measures of KCL-evoked transients and choline clearance (obtained from separate groups of mice). $\boldsymbol{e}$, Example of amperometric traces (current sampled at $1 \mathrm{~Hz}$ ) recorded at $10 \mathrm{~min}$ following BF-stim and in response to depolarization (see pressure ejection time point on abscissa). $\boldsymbol{f}$, In BF-sham, the amplitudes of depolarization-induced cholinergic transients did not differ between the strains ( $n=3-4$ per strain). In contrast, measures taken 10 or 90 min after BF-stim (separate groups of mice; $n=4-6$ per strain and time point) indicated an attenuation of the amplitudes of evoked ACh release in $\mathrm{CHT}^{+/-}$mice (see ANOVAs in Results). $\boldsymbol{g}$, Examples of amperometric traces (current sampled at $10 \mathrm{~Hz}$ ) indicating clearance of exogenous choline (1 mm; see pressure ejection time point on abscissa) at 10 min after BF-stim. $\boldsymbol{h}, \boldsymbol{i}$, Compared with wild-type mice, in $\mathrm{CHT}^{+/-}$mice both the time required to decrease choline concentrations from $40 \%$ to $80 \%$ of peak levels $(\boldsymbol{h}$; the hemicholinium-3-dependent component of the clearance function — see text) and the rate of choline uptake during this period (i) were significantly attenuated. However, choline clearance capacity was fully recovered at 90 min after BF-stim (see ANOVAs in Results; multiple comparisons: ${ }^{*} p<0.05 ;{ }^{* *} p<0.01$; ${ }^{* * *} p<0.001$ ).

hydrolysis of new released ACh (Parikh et al., 2004; Parikh and Sarter, 2006). The capacity of cortical CHTs to clear extracellular choline was evaluated by assessing the clearance of exogenously applied choline (1 $\mathrm{mM} ; 50-80 \mathrm{nl})$. Care was taken to generate choline signals with corresponding amplitudes in all animals $(10-15 \mu \mathrm{M})$ (Parikh and Sarter, 2006). At the end of the recording sessions, animals were transcardially perfused with $30 \mathrm{ml}$ of ice-cold saline followed by $10 \%$ formalin. Brains were post-fixed in formalin and cryoprotected in 30\% sucrose solution. Coronal sections were sliced and Nissl stained for verification of intracortical placements of microelectrodes.

Basal extracellular choline concentration. Basal extracellular choline levels were determined in the medial prefrontal cortex from mice during
60 min electrode stabilization period as described previously (Parikh and Sarter, 2006). Briefly, the in vivo background current recorded on sentinel channels was subtracted from ChOase-coated sites. The difference in current was divided by the calibration slope of the ChOase-coated channel.

Analyses of transients. Currents recorded via enzyme-coated sites were self-referenced by subtracting currents recorded on sentinel sites (Parikh et al., 2008, 2010) in cases when background noise levels on enzymecoated channels exceeded $10 \mathrm{pA}$ (equivalent to $2 \mu \mathrm{M}$ choline) or pressure-ejection artifacts occurred. Amplitudes of choline signals were determined by recording peak change in current over baseline values, and by dividing the difference by choline sensitivity obtained from in 
vitro calibration. Measures of in vivo $\mathrm{CHT}$ capacity were derived from clearance kinetics of signals generated from exogenously applied choline. For statistical comparisons, two parameters of choline clearance were derived: (1) $T_{40-80}$, time (in seconds) required for the signal to decline between $40 \%$ and $80 \%$ of the maximal amplitude; and (2) choline uptake rate $(\mu \mathrm{m} / \mathrm{s})$, slope of the linear regression of data points on the clearance curve corresponding to $T_{40-80}$. These parameters were previously shown to reflect the hemicholinium-3-sensitive component of the choline clearance curve (Parikh and Sarter, 2006; Parikh et al., 2006).

Subcellular fractionation and immunoblot analyses. Animals were decapitated under urethane anesthesia. Brains were removed, and tissues were dissected on an ice-cold Petri dish. Isolated tissues were homogenized in ice-cold $0.32 \mathrm{~m}$ sucrose. The homogenate was centrifuged at $1000 \times g$ for $4 \mathrm{~min}$ at $4^{\circ} \mathrm{C}$ to remove cellular debris. A synaptosomal pellet was obtained by spinning the resulting supernantant at $12,500 \times g$ for $15 \mathrm{~min}$. Subcellular fractions consisting of the synaptic plasmamembrane-enriched (LP1) and vesicular-membrane enriched (LP2) fractions were isolated as described previously (Gates et al., 2004; Apparsundaram et al., 2005; Parikh et al., 2006). Briefly, the synaptosomal pellet was lysed in by homogenization in $5 \mathrm{~mm}$ HEPES-NaOH, $\mathrm{pH}$ 7.4 , containing $1.0 \mu \mathrm{g} / \mathrm{ml}$ leupeptin, $1.0 \mu \mathrm{g} / \mathrm{ml}$ aprotinin, $1.0 \mu \mathrm{g} / \mathrm{ml}$ pepstatin, and $250 \mu \mathrm{g} / \mathrm{ml}$ phenylmethylsulfonyl fluoride. LP1 fraction was collected by spinning the lysate at $15,000 \times g$ for $20 \mathrm{~min}$. The resultant supernantant was centrifuged at $200,000 \times g$ for $30 \mathrm{~min}$ to obtain the LP2 fraction using a Beckman-Coulter TL100 ultracentrifuge. Proteins were extracted from each fraction with $1 \%$ SDS, 5 mм HEPES-KOH, pH 7.3, 1 mм EDTA, 1 mм EGTA, and a protease inhibitor cocktail. Protein concentrations were determined by using a modified Lowry Protein Assay (Pierce). Equal quantities $(25 \mu \mathrm{g})$ of protein from each fraction were subjected to immunoblot analysis, and each sample was assayed in duplicate. Proteins were separated on $4-15 \%$ Tris $\mathrm{HCl}$ polyacrylamide gels and transferred in PVDF membranes. A mouse anti-CHT monoclonal antibody (clone 62-2E8; Millipore) (Ferguson et al., 2003) was used at 1:1000 dilution for the immunodetection of CHT bands. The blots were exposed to a peroxidase-conjugated anti-mouse secondary antibody and ECL Advance chemiluminescent substrate (GE Healthcare). The resulting chemiluminescent signal was acquired with a Molecular Imager Chemidoc EQ system (Bio-Rad). Densitometric analysis of CHTimmunoreactive bands in the LP1 and LP2 fractions was performed by calculating the integrated pixel densities using NIH ImageJ software. To accommodate for any differences in sample loading between different samples, the density of CHT-immunoreactive bands were normalized to the levels of $\beta$-tubulin-immunoreactive bands for each sample analyzed.

Behavioral methods and postsession tissue harvesting: housing and water deprivation. Access to water was restricted to a $4 \mathrm{~min}$ period following each operant training or practice session. Their average intake of water during this free period was $1.92 \mathrm{ml}$. Saccharin water was also provided as a reward during task performance. On average, mice receive $0.45 \mathrm{ml}$ of $0.2 \%$ saccharin during task ( $\sim 6 \mu \mathrm{l}$ per reward). On days not tested, water access in their home cage was increased to a total duration of $20 \mathrm{~min}$. Food (Rodent Chow, Harlan Teklad) was available ad libitum. Mice began experiments at 12 weeks of age when they weighed 20-30 g. Experiments occurred at the same time each day, 5-6 d/week. Operant chambers, training, and testing conditions and methods were previously described in detail (St Peters et al., 2011b). The main components of the sustained attention task (SAT) are illustrated in Figure 3. In the final version of the SAT, mice were presented with signals with three durations $(0.5,0.05$, and $0.025 \mathrm{~s})$. The sequence of signal and nonsignal events was pseudo-randomized [intertrial interval (ITI): $12 \pm 3 \mathrm{~s}$ ]. For SAT sessions involving distractor presentation (dSAT), including the final session before tissue harvesting, the house light and panel light above the cue light flash asynchronously at $0.5 \mathrm{~Hz}$ in the middle portion (minutes $8-24$ ) of the 40 min session (see Fig. 4b). Performance was analyzed based on SAT scores. The SAT collapses performance in both signal and nonsignal trials into one measure (SAT $=\%$ hits $-\%$ false alarms) $[2$ (\%hits $+\%$ false alarms $\left.)(\% \text { hits }+\% \text { false alarms })^{2}\right]$. This score ranges from +1.0 to -1.0 , with +1.0 indicating that all recorded responses were hits or correct rejections and -1.0 indicating all recorded responses were misses or false alarms. Nonperforming (NP) mice were placed into the operant cham- bers daily under conditions similar to the performing counterparts (frequency of being placed in operant chambers, time of day, and whether the houselight was on or off).

On the day of tissue harvest, immediately at the end of the dSAT session urethane was administered (1.25-1.5 g/kg, i.p.) to the mice, and then they were decapitated. The cerebellum, brainstem, and olfactory bulb were removed. The hemispheres were separated, and landmarks (hippocampus and striatum) were used to divide each hemisphere on a rostral-caudal axis. The striatum was removed from each hemisphere and pooled, and the remaining subcortical structures from each section were discarded. The remaining frontal and parietal cortices were harvested. All sections were stored in $1.4 \mathrm{ml} 0.32 \mathrm{M}$ sucrose on ice until tissues from a second mouse of the same genotype were obtained. Tissues from two animals were pooled for all subsequent steps. Tissues were homogenized using 16 strokes. The homogenized liquid was centrifuged for $4 \mathrm{~min}$ at $3000 \mathrm{rpm}$. The supernatant was then centrifuged at 10,800 rpm for $10 \mathrm{~min}$. The liquid was removed, and the synaptosomal pellet was frozen at $-80^{\circ} \mathrm{C}$ and shipped to V.P. at Temple University for immunoblot analyses (see above).

Statistical analyses. Statistical analyses were performed using SPSS/ PC+ version 17.0 (SPSS). Strain-dependent effects on basal choline and ACh levels were analyzed using unpaired Student's $t$ tests. Repeatedmeasures mixed-factor ANOVAs were used to analyze the effects of genotype (two levels) and BF-stim (two levels) on measures of ACh release with dialysate collection periods (three levels; before BF-stim, during BF-stim, and after BF-stim) as the within-subject variable. The effects of BF-stim (two levels), genotype (two levels), and time points (10 and 90 min after BF-stim; two levels) on choline signal amplitudes, clearance kinetics, and $\mathrm{CHT}$ densities were analyzed using mixed-factor ANOVAs. Mixed-factor repeated-measures ANOVAs were also used to analyze attentional performance as well as the effects of performance (two levels) and genotype (two levels) on the redistribution of CHTs between the two fractions across multiple brain regions. The Greenhouse-Geisser sphericity correction was applied as needed. Post hoc comparisons between groups were conducted using Fisher's least significant difference test or planned $t$ tests. Exact $p$ values are reported as recommended by Greenwald et al. (1996).

\section{Results}

\section{Evoked cortical acetylcholine release and choline clearance in vivo}

The first series of experiments determined, in vivo, the impact of a reduced expression of the presynaptic CHT on the capacity of cortical cholinergic afferents to release ACh and to clear exogenous choline in response to BF-stim. These experiments used microdialysis methods as well as enzyme-coated microelectrodes to measure basal and evoked ACh release and choline clearance (Parikh and Sarter, 2006; Parikh et al., 2007, 2010; St Peters et al., 2011a). We used electrical stimulation of the BF to simulate the sustained alterations in cholinergic neuron activity observed during attentional task performance (Kozak et al., 2007; St Peters et al., 2011a). Our stimulation parameters corresponded to those used previously to determine the effects of BF activation on sensory coding (Edeline et al., 1994; Goard and Dan, 2009) and cognitive processes (McLin et al., 2002; Boix-Trelis et al., 2006). Sampling was performed in the right medial prefrontal cortex because of our prior findings indicating sustained increases in cholinergic activity in this region during attentional performance (St Peters et al., 2011a). The focus on this region was also consistent with the findings on attentional performance-induced subcellular distribution of CHTs (see below). Figure 1 illustrates the placement of stimulation electrodes, microdialysis probes, and enzyme-coated microelectrodes; the timeline for electrochemical measures; and the findings from this set of experiments. 
Properties of choline-sensitive electrodes

The microelectrodes $(n=30)$ used for these experiments displayed a sensitivity of $6.72 \pm 0.76 \mathrm{pA} / \mu \mathrm{M}$ and an LOD of $339.05 \pm 37.54 \mathrm{~nm}$ for choline. Furthermore, the microelectrodes were $194.19 \pm 45.49$ times more selective for choline compared with AA. The responses of the electrodes to increasing concentrations of choline (up to $80 \mu \mathrm{M}$ ) were highly linear $\left(R^{2}=\right.$ $0.993 \pm 0.001)$. These calibration parameters indicated that the microelectrodes were capable of detecting choline in a sensitive and selective manner.

Baseline ACh release, basal $\mathrm{K}^{+}$-evoked release, extracellular choline levels, and CHT-mediated choline clearance

In the absence of BF-stim, basal ACh release, measured by using microdialysis, did not differ significantly between the genotypes $\left[\mathrm{CHT}^{+/+}: 682.57 \pm 106.51 \mathrm{fmol} / \mu \mathrm{l} / \mathrm{min}\right.$ (mean $\pm \mathrm{SEM}$ ); $\left.\mathrm{CHT}^{+/-}: 494.15 \pm 53.59 \mathrm{fmol} / \mu \mathrm{l} / \mathrm{min} ; t_{(7)}=0.69 ; p=0.51\right]$. Likewise, KCL-evoked cholinergic transients, assessed by pressure ejections of KCL $(70 \mathrm{~mm})$ into the vicinity of cholinesensitive recording sites, indicated that the basal capacity of cholinergic neurons to release ACh was not affected by genotype [ANOVA on the effects of genotype and time; note that time (10 vs 90 min after BF-sham) was a between-subject variable; genotype: $F_{(1,10)}=0.85 ; p=0.38$; time: $F_{(1,10)}=15.88 ; p=0.003$; interaction: $F_{(1,10)}=0.72 ; p=0.42$; Fig. 1$]$.

Basal extracellular choline concentrations were determined in vivo by using choline-sensitive microelectrodes and amperometry (Parikh and Sarter, 2006). Basal extracellular choline concentrations did not differ between the genotypes (mean \pm SEM: $\mathrm{CHT}^{+/+}: 3.63 \pm 0.38 \mu \mathrm{M} ; \mathrm{CHT}^{+/-}: 3.93 \pm 0.75 \mu \mathrm{M} ; t_{(4)}=0.36$; $p=0.74)$, consistent with the major determinant of extrasynaptic choline levels as derived from extraneuronal sources.

The capacity of CHT-mediated choline clearance was determined by infusing exogenous choline $(1.0 \mathrm{~mm})$ through a guide targeting the center between the four Pt recording sites on the microelectrodes. The analyses of choline clearance focused on the time required for the current to decline from 40 to $80 \%$ of $T_{40-80}$, and, for this period, we determined the choline clearance rate (the linear regression of currents for this period). We previously demonstrated that these measures reflect HC-3-dependent choline clearance (Fig. 1 in Parikh and Sarter, 2006). At baseline, the capacity of presynaptic cholinergic terminals to clear choline did not differ between the genotypes and the two time points $\left(T_{40-80}\right.$ : main effects of genotype, time, interaction: all $p>0.05$; Fig. $1 \mathrm{~h}$; uptake rate: all $p>0.05$; Fig. $1 i$ ). Thus, at baseline, and in the absence of demands on cholinergic activity, CHT heterozygosity does not impact ACh release or choline clearance capacity.

Reduced cholinergic release capacity during and after BF-stim Whereas increases in cortical ACh release and choline clearance rates were observed following stimulation of the wild-type $\mathrm{BF}$, these parameters were significantly diminished following BFstim in $\mathrm{CHT}^{+/-}$mice. ACh release was measured using microdialysis before, during, and after the $20 \mathrm{~min}$ BF-stim period (Fig. 1c). As both genotypes released similar absolute levels of ACh at baseline (see above), data were expressed as a percentage of basal release and analyzed by ANOVA on the effects of genotype and collection period [three levels; after BF-stim (30 and 40 min collections), during BF-stim (50 and 60 min collections), and after BF-stim (70 and 80 min collections)]. This analysis indicated the efficacy of BF-stim in increasing ACh release in both genotypes (main effect of period: $F_{(2,23)}=6.20 ; p=0.013$; before BF-stim: $101.26 \pm 2.84 \%$; during BF-stim: $177.51 \pm 25.04 \%$; after BFstim: $118.10 \pm 11.75 \%$; multiple comparisons indicated higher levels of ACh release during BF-stim when compared with before and after BF-stim periods; both $p<0.04$ ). These increases in ACh release in $\mathrm{CHT}^{+/-}$mice were generally attenuated (main effect of genotype: $F_{(1,16)}=6.02 ; p=0.026 ; \mathrm{CHT}^{+/+}: 151.24 \pm 15.95 \%$; $\left.\mathrm{CHT}^{+1-}: 108.60 \pm 9.34 \%\right)$. There was no interaction between the effects of period and genotype $\left(F_{(2,16)}=2.30 ; p=0.13\right)$, reflecting that $\mathrm{ACh}$ release in $\mathrm{CHT}^{+/-}$mice remained below wild-type levels during and after BF-stim. Inspection of Figure $1 c$ indicates that toward the end of the simulation (collection at 60 min), BF-stim no longer stimulated $\mathrm{ACh}$ release in $\mathrm{CHT}^{+/-}$mice while release levels remained elevated ( $\sim 175 \%$ over baseline) in wild-type animals.

Both tonic (scale of minutes) and phasic (seconds; "transients") modes of neurotransmission characterize cortical cholinergic activity (Parikh et al., 2007; Hasselmo and Sarter, 2011). These transients can be measured using amperometry and choline-sensitive microelectrodes, and the capacity for phasic cholinergic activity can be probed by depolarizing synaptic terminals (Parikh et al., 2004; Parikh and Sarter, 2006). In CHT ${ }^{+/+}$ mice, BF-stim did not affect the capacity of cholinergic neurons to release $\mathrm{ACh}$ as a result of potassium-induced depolarization, neither at $10 \mathrm{~min}$ nor at $90 \mathrm{~min}$ after BF-stim (Fig. $1 \mathrm{f}$ ). In contrast, depolarization-evoked amplitudes were diminished in CHT heterozygous animals, with only partial and insignificant recovery after $90 \mathrm{~min}$. ANOVA of the effects of BF-stim and genotype on the amplitude of $\mathrm{K}^{+}$-evoked cholinergic transients, recorded $10 \mathrm{~min}$ after $\mathrm{BF}$-stim, indicated a main effect of genotype $\left(F_{(1,14)}=11.07 ; p=0.005\right)$, a main effect of BF-stim $\left(F_{(1,14)}\right.$ $=17.44 ; p=0.001)$, and a significant interaction between the effects of these two factors $\left(F_{(1,14)}=4.77 ; p=0.04\right.$; for multiple comparisons, see Fig. $1 f$ ). Recordings at 90 min after BF-stim (in a separate group of animals) reproduced these findings (genotype: $F_{(1,12)}=11.93 ; p=0.005 ;$ BF-stim: $F_{(1,12)}=22.72 ; p=0.001$; interaction: $F_{(1,12)}=11.11 ; p=0.006$; for multiple comparisons, see Fig. $1 f$ ). Collectively, these results indicate that BF-stim attenuated the amplitude of evoked cholinergic transients in $\mathrm{CHT}^{+/-}$ mice and that amplitudes of the transients did not return to baseline levels when measured 90 min after BF-stim. As will be detailed below, this latter finding differs from the recovery of measures of choline clearance and the subcellular distribution of CHTs at 90 min after BF-stim.

\section{Reduced choline clearance capacity following BF-stim}

In $\mathrm{CHT}^{+/+}$mice, BF-stim did not lengthen the time required to clear choline $\left(T_{40-80}\right.$; Fig. $\left.1 \mathrm{~h}\right)$ and did not lower choline uptake rate (Fig. $1 i$; see above for justification of clearance measures). In contrast, in $\mathrm{CHT}^{+/-}$mice, $\mathrm{BF}$-stim reduced the ability of cholinergic terminals to clear exogenous choline (traces are exemplified in Fig. $1 g$ ). However, this effect was restricted to the early time point $\left(10 \mathrm{~min}\right.$ after BF-stim, $T_{40-80}$ : genotype: $F_{(1,10)}=$ $13.17 ; p=0.005$; BF-stim: $F_{(1,10)}=13.04 ; p=0.005$; interaction: $F_{(1,10)}=11.75 ; p=0.006$; uptake rate: genotype: $F_{(1,10)}=10.92$; $p=0.008$; BF-stim: $F_{(1,10)}=5.92 ; p=0.008$; interaction: $F_{(1,10)}=$ $3.43 ; p=0.09$; for multiple comparisons, see Fig. $1 h, i)$. Clearance capacity was recovered by $90 \mathrm{~min}\left(T_{40-80}\right.$ : main effects and interaction, all $p>0.42$; uptake rate: main effects and interaction, all $p>0.69)$.

\section{Subcellular distribution of CHTs and effects of BF-stim}

Baseline CHT densities in plasma membrane versus vesicular membrane-enriched fractions (LP1 vs LP2)

We used a design similar to that described in Figure $1 d$ to determine the basal distribution of CHTs in plasma membrane and 

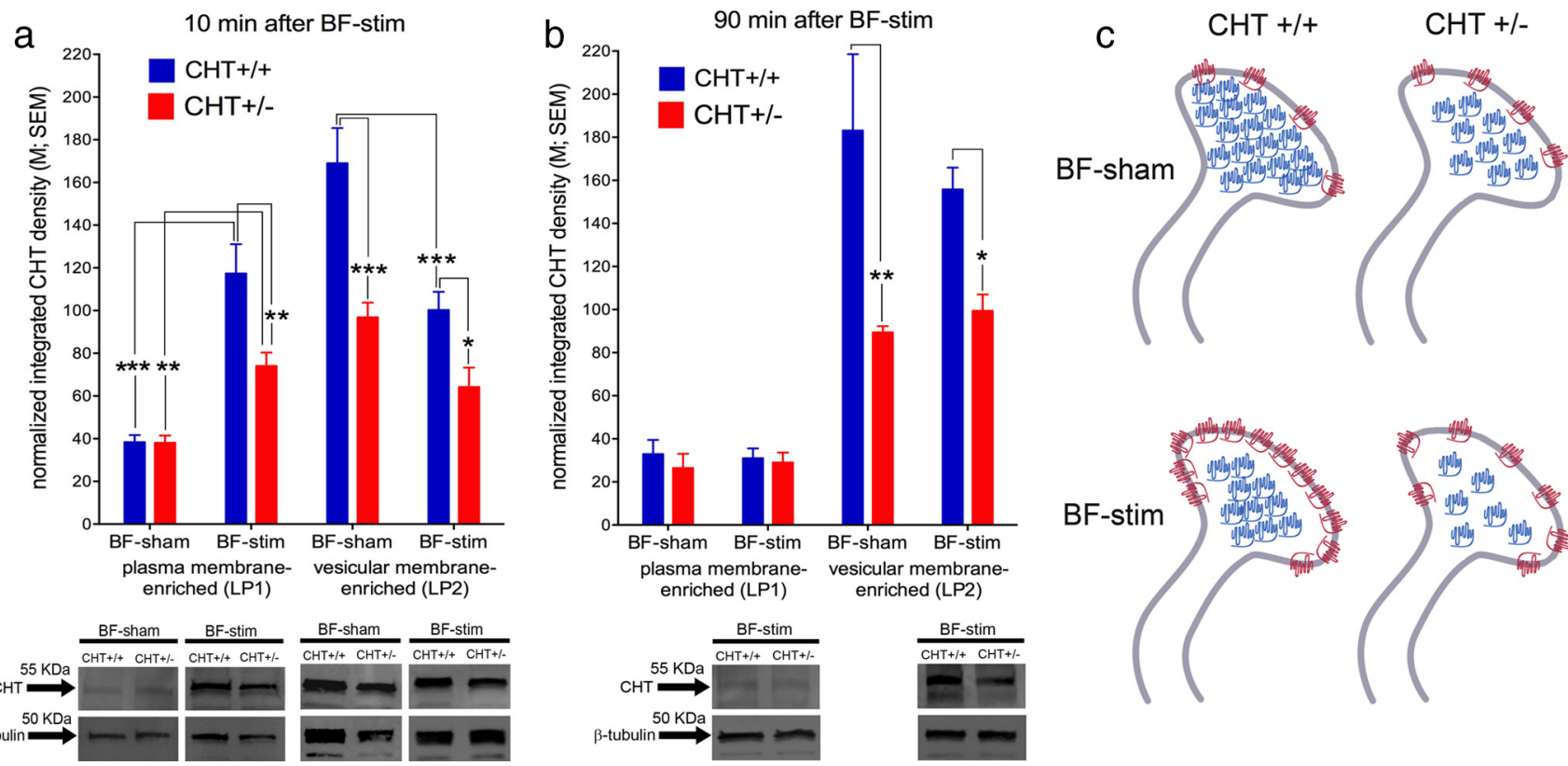

Figure 2. $\quad \boldsymbol{a}, \boldsymbol{b}$, CHT densities in subcellular synaptosomal fractions from frontal cortex (LP1: synaptosomal plasma membrane-enriched fraction; LP2: vesicular membrane-enriched fraction) obtained from tissues harvested $10 \mathrm{~min}(\boldsymbol{a})$ or $90 \mathrm{~min}(\boldsymbol{b})$ after termination of BF-stim ( $n=6-10$ per time point and strain; see ANOVAs in Results). In BF-sham, the LP2 fraction of CHT ${ }^{+/+}$mice contained a 4.4-fold greater density of CHTs than the LP1 fraction. In $\mathrm{CHT}^{+/-}$mice, this ratio was smaller (2.5-fold), reflecting the lower density of CHTs at baseline in the LP2 fraction in these mice. Moreover, lower intracellular CHT densities almost completely accounted for the overall lower total density of synaptosomal CHTs in heterozygous animals. BF-stim increased the density of CHTs in synaptosomal plasma membranes (LP1) in both strains; however, in $\mathrm{CHT}^{+/-}$mice, this increase was smaller. $\boldsymbol{b}$, At 90 min after BF-stim, the densities of CHTs had returned to baseline values $\left({ }^{*} p<\right.$ $0.05 ;{ }^{* *} p<0.01 ;{ }^{* * *} p<0.001$; multiple comparisons based on significant ANOVA; see Results). Representative immunoblots are shown below the respective bars. As detailed in Results, the stimulation-induced changes in CHT densities in the two fractions were almost completely proportional in both strains, suggesting that outward trafficking rates were similar across strains. Furthermore, in $\mathrm{CHT}^{+/-}$mice, the lower intracellular CHT density (LP2 fraction) at baseline was sufficient to predict the attenuated effects of BF-stim on CHT density in plasma membrane-enriched fraction (LP1). This finding is summarized and illustrated in c (note that the diagram does not define intracellular domains but merely symbolizes the proportions of CHTs found in LP2 fractions).

intracellular locations, and the effects of BF-stim on CHT density in synaptosomal plasma membrane-enriched versus vesicleenriched fractions (LP1 vs LP2 fraction; see Materials and Methods for subcellular fractionation strategy and immunoblotting methods). We previously confirmed that the synaptic vesicle markers VAChT and synaptophysin are predominantly present in the (vesicular membrane-enriched) LP2 fraction, whereas the NMDA receptor subunit $2 \mathrm{~A} / \mathrm{B}$ is predominantly present in the (plasma membrane-enriched) LP1 fraction (Apparsundaram et al., 2005). The analysis of the effects of BF-stim on CHT distribution was restricted to the medial frontal cortex because, as will be detailed below, this was the only region in which CHT distribution was affected by attentional performance in wild-type mice. Tissues were harvested 10 or 90 min following the completion of BF-stim.

In nonstimulated wild-type mice, the larger proportion (relative to the total homogenate) of CHTs was concentrated in the vesicular-enriched LP2 fraction (81.50\%). CHT heterozygosity reduced $\mathrm{CHT}$ protein in the total homogenate to $65 \%$ of the level in wild-type mice. The lower CHT density in the LP2 fraction of heterozygous mice (57.28\%) approximately accounted for the overall lower protein levels. The finding that basal CHT densities in the synaptosomal plasma membrane did not differ between $\mathrm{CHT}^{+/+}$and $\mathrm{CHT}^{+/-}$mice corresponds with the result that, at baseline, measures of cholinergic neurotransmission and choline clearance likewise did not differ between the genotypes (see above).

\section{Effects of BF-stim}

In wild-type mice at $10 \mathrm{~min}$ after BF-stim (Fig. 2a), the density of CHTs in the plasma membrane (LP1) was increased. In contrast, BF-stim decreased the density of CHTs located in intracellular domains (LP2). These effects were attenuated in $\mathrm{CHT}^{+/-}$mice. For the analyses of both LP1 and LP2 fractions, there were main effects of BF-stim and genotype as well as significant interactions between these two factors (LP1: main effects of BF-stim: $F_{(1,16)}=$ 48.49; $p<0.001$; genotype: $F_{(1,16)}=6.99 ; p=0.02$; interaction: $F_{(1,16)}=6.79 ; p=0.02 ;$ LP2: BF-stim: $F_{(1,16)}=21.50 ; p<0.001$; genotype: $F_{(1,16)}=24.56 ; \mathrm{p}=<0.001$; interaction: $F_{(1,16)}=2.73$; $p=0.11$; for multiple comparisons, see Fig. $2 a$ ).

Inspection of the data provided additional insights. In both genotypes, the increases in CHTs in the LP1 fraction and the decreases in the LP2 fraction were nearly completely proportional, as indicated by stable LP1 + LP2 sums (sums of means; $\mathrm{CHT}^{+/+}$: BF-sham: 207.37; BF-stim: 217.69; CHT $^{+/-}$: BF-sham: 134.89; BF-stim: 138.27). This observation is consistent with the "synaptic vesicle CHT trafficking" hypothesis of Ferguson and Blakeley (2004), suggesting that cholinergic activity triggers outward trafficking of CHTs.

Furthermore, BF-stim reduced the ratios between the densities of CHTs in the two fractions to corresponding values in both genotypes. In wild-type mice and following BF-sham, the LP1/ LP2 CHT ratio was 0.22 (one CHT in the membrane for almost every five in intracellular domains). BF-stim changed this ratio to almost 1. In $\mathrm{CHT}^{+/-}$mice, the corresponding ratios shifted from 0.4 to 0.8 . Therefore, in $\mathrm{CHT}^{+/-}$mice, a lower intracellular density of CHTs at baseline, perhaps combined with a genotype-independent unavailability of a significant proportion of intracellular CHTs for BF-stim-induced translocation, were responsible for the limited stimulation-induced increases in cholinergic neurotransmission.

At 90 min after BF-stim, CHT distribution had reverted to baseline levels (LP1: main effects of BF-stim, genotype and inter- 
action: all $p>0.09$; LP2: genotype: $F_{(1,8)}=15.88 ; p=0.004$; effects of BFstim and interaction: both $p>0.35$; Fig. $2 b)$. At this time point, LP1 CHT densities were identical between the strains and no longer affected by BF-stim. Likewise, the lower density of CHTs in LP2 fractions of $\mathrm{CHT}^{+/-}$mice was restored at 90 min after BF-stim. The diagram in Figure $2 c$ illustrates the collective findings from these experiments.

\section{Impaired attentional performance and performance-induced subcellular redistribution of $\mathrm{CHTs}$}

The experiments described above used BF-stim to test the capacity of cortical cholinergic inputs to sustain high levels of cholinergic neurotransmission. Although the stimulation parameters corresponded with those shown to evoke physiologically and behaviorally meaningful effects (Edeline et al., 1994; McLin et al., 2002; Boix-Trelis et al., 2006; Goard and Dan, 2009), this third series of experiments was designed to demonstrate that the cholinergic capacity limitations of $\mathrm{CHT}^{+/-}$ mice impact sustained attentional performance. Such performance is mediated by, and requires, relatively high levels of cortical cholinergic neurotransmission (Kozak et al., 2007; St Peters et al., 2011a). Attentional performanceassociated increases in cholinergic activity are further augmented by performance challenges such as distractors (St Peters et al., 2011a). Such distractors activate mechanisms designed to stabilize and recover attentional performance, including the enhancement of the processing of targets and the filtering of distractors (Sarter et al., 2006; Demeter et al., 2008, 2011; Nuechterlein et al., 2009). Higher levels of right PFC cholinergic activity are hypothesized to optimize such detection and filtering processes (Hasselmo and Sarter, 2011). Therefore, we used the distractor version of the sustained attention task that was recently adapted and validated for use in mice (dSAT) (St Peters et al., 2011b) to test the hypothesis that such performance reveals, and suffers from, the limited cholinergic capacity of $\mathrm{CHT}^{+/-}$mice.

The main components of this task are illustrated in Figure $3 a$. As detailed in Materials and Methods, mice were trained to the criterion and then familiarized with the visual distractor. The distractor was presented during blocks 2 and 3 of a total of 5 blocks of trials (minutes $8-24$ of a total of $40 \mathrm{~min} / \mathrm{session}$ ). Tissues were harvested immediately after the final dSAT performance session. Tissues from two mice per region needed to be pooled for subfractionation and immunoblotting.

Mice of both genotypes acquired all five stages of task acquisition (see Materials and Methods) within the same number of sessions (main effects of genotype and stage genotype: both $p>$
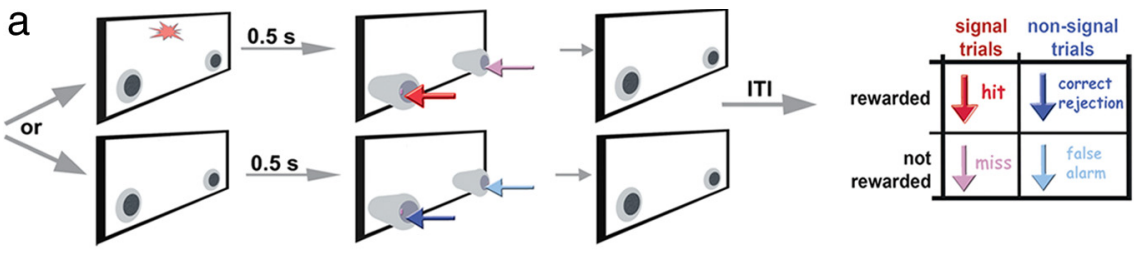

b
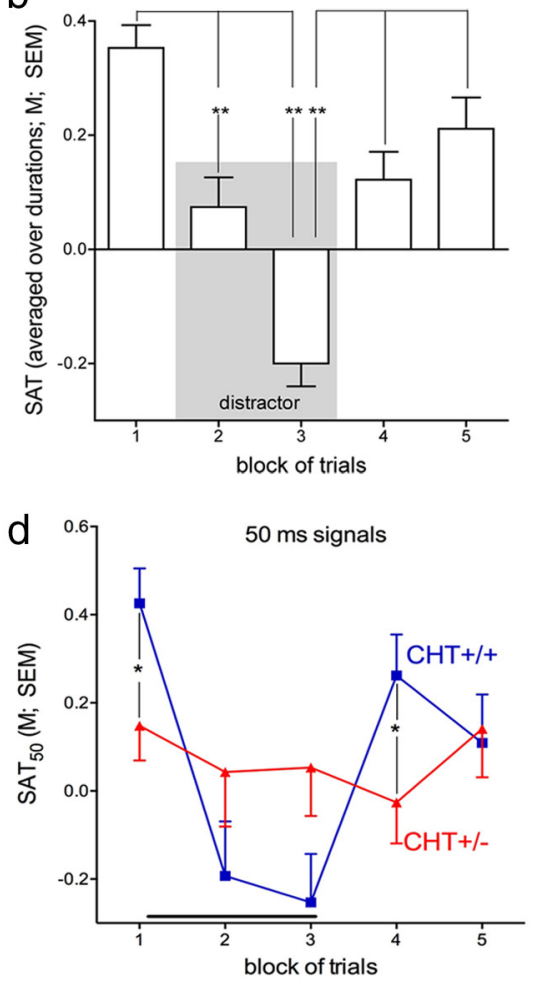

C
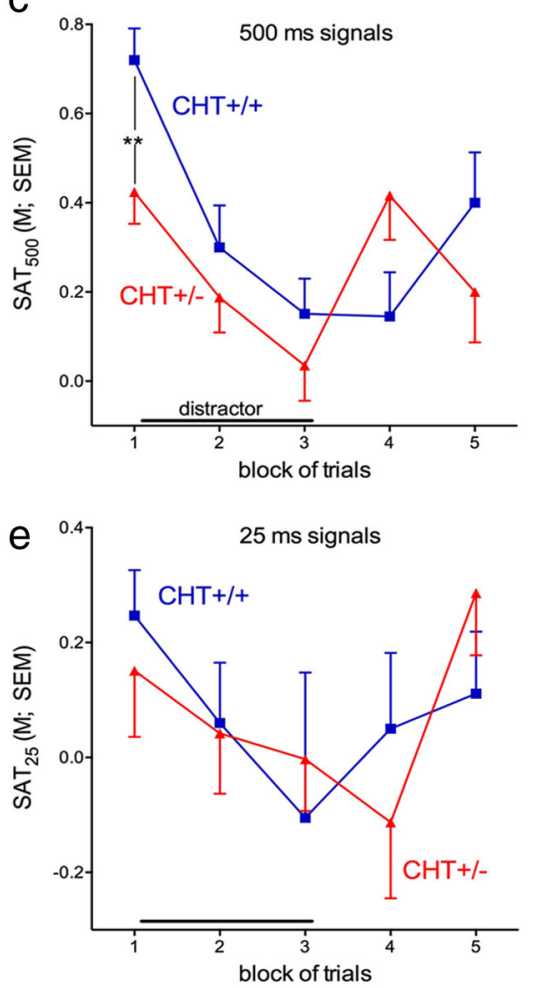

Figure 3. Performance of wild-type and $\mathrm{CHT}^{+/-}$mice in the distractor SAT, just before tissue harvesting for the analysis of performance-induced changes in subcellular CHT distribution. a shows the main components of the SAT. Following a variable ITI, presentation of either a signal (variable duration: $500-25 \mathrm{~ms}$ ) or a nonsignal was followed $0.5 \mathrm{~s}$ later by the extension of two nal trials consisted of left and right nose-pokes and were recorded as hits and correct rejections, respectively. Incorrect responses were misses and false alarms, respectively, and initiated an ITI (see color-coded response arrows matching the outcome matrix on version of the SAT; the distractor consisted of the house light and panel light above the cue light flash asynchronously at $0.5 \mathrm{~Hz}$ in the middle portion (minutes $8-24$ ) of the 40 min session (blocks 2 and 3 of 5 blocks at 8 min each). The SAT scores depicted in $\boldsymbol{b}$ - $\boldsymbol{e}$ (hificantly impaired the performance of all animals, with performance reaching chance level (SAT scores: $<0.17$; main effect of

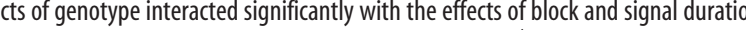
animals (for omnibus ANOVAs, see Results; multiple comparisons based on post hoc two-way ANOVAs followed by $t$ tests; ${ }^{*} p<$ $\left.0.05 ;{ }^{* *} p<0.01 ;{ }^{* * *} p<0.001\right)$.

0.18). Animals required on average $58 \mathrm{~d}$ (sessions) of training to reach criterion performance (see Materials and Methods).

Performance immediately before tissue harvesting

Brain tissue harvesting was preceded by a session during which the distractor was presented during task blocks 2 and 3 ( $8 \mathrm{~min} /$ block; 5 blocks total; Fig. 3a,b). Performance was analyzed using a score that combines signal and nonsignal trial performance into one score (SAT score). This score varies from +1 (all responses were hits and correct rejections), to zero (50\% accuracy in signal and nonsignal trials) and -1 (all responses were misses and false alarms). SAT scores were calculated for individual signal duration $\left(\mathrm{SAT}_{500 ; 50,25}\right)$. 
Reflecting the detrimental effects of the distractor on both the detection of signals and the correct rejection of nonsignal events, the distractor impaired the performance of both genotypes (main effect of block: $F_{(4,72)}=9.14 ; p<0.001$; for multiple comparisons, see Fig. $3 b$ ). Furthermore, performance depended on signal duration, indicating again that animals detected longest signals more reliably than the two shorter signals (duration: $F_{(2,36)}=$ 15.91; $p<0.001$; duration $\times$ block: $p=0.16$ ).

This mixed-model ANOVA also indicated that the performance of the two genotypes differed over blocks and signal duration (three-way interaction: $F_{(8,144)}=2.84 ; p=0.006$; Fig. $3 c-e)$. To locate the source for this interaction, the interactions between the effects of genotype and block were analyzed for each signal duration. Significant interactions were found for $\mathrm{SAT}_{500}$ $\left.F_{(4,72)}=3.12 ; p=0.02\right)$ and $\operatorname{SAT}_{50}$ scores $\left(F_{(4,72)}=3.48 ; p=\right.$ 0.01 ). Multiple comparisons (Fig. $3 c, d$ ) indicated that even before the distractor was turned on (block 1), and for both measures, $\mathrm{CHT}^{+/-}$animals' performance was significantly lower when compared with wild-type animals. The distractor suppressed the performance of both genotypes to chance levels. During the postdistractor period, $\mathrm{CHT}^{+/-}$mice did not recover their performance as well as wild-type mice, as indicated by a significantly lower $\mathrm{SAT}_{50}$ score during the immediate postdistractor block of trials $\left(t_{(18)}=2.19 ; p=0.04\right)$. Finally, the relative number of errors of omission remained below 15\% for both groups of animals and did not increase during the distractor period (main effects and interaction: all $p>0.35$ ).

Performance-induced subcellular redistribution of CHTs

Within 2 min of completion of the dSAT session, brain tissues were harvested from performing mice and nonperforming controls (see Materials and Methods for details). Similar to performing mice, NP mice were extensively handled and placed daily into the operant chambers for the duration equivalent to performance sessions. However, the task was never initiated. As the primary comparisons were between performing wild-type and $\mathrm{CHT}^{+/-}$ mice, data from NP mice served to revalidate our methods and determine baseline CHT distribution from additional regions in both hemispheres. Reliable immunoblotting required the pooling of cortical tissues from two mice per genotype. Striatal CHT measures were based on tissues pooled from both hemispheres from two mice.

\section{Subcellular CHT densities in NP mice}

Confirming the baseline CHT distribution described above in the experiment on the effects of BF-stim, the density of CHTs in the synaptosomal plasma membrane-enriched LP1 fraction did not differ between $\mathrm{CHT}^{+/+}$and $\mathrm{CHT}^{+/-}$mice (main effect of genotype: $F_{(1,8)}=0.27 ; p=0.62$; Fig. $4 a$ ). For cortical tissues, LP1 CHT densities were generally higher in the left hemisphere $\left(F_{(1,18)}=44.26 ; p<0.001\right)$. CHT density in LP2 fractions from $\mathrm{CHT}^{+1-}$ mice were lower in all tissues when compared with those from wild-type mice $\left(F_{(1,6)}=67.35 ; p<0.001\right.$; for multiple comparisons, see Fig. $4 b$ ). As was the case in the analysis of baseline subcellular CHT densities in the experiment on the effects of BF-stim, the lower total (over all tissues) synaptosomal CHT density in heterozygous mice $(-52 \%)$ was largely accounted for by lower intracellular CHT levels $(-45 \%)$.

\section{Effects of attentional performance}

Following completion of the attentional performance session, CHT densities in LP1 fractions of wild-type animals were generally higher than in $\mathrm{CHT}^{+/-}$mice (main effect of genotype: $F_{(1,8)}$ $=5.97 ; p=0.04$ ). Multiple comparisons indicated a significantly higher level in the LP1 fraction of synaptosomes obtained from the right frontal cortex (for multiple comparisons, see Fig. 4c). Additional post hoc analyses indicated that this effect of performance reflected an increase in the LP1 CHT density in wild-type mice but not $\mathrm{CHT}^{+/-}$mice when compared with nonperforming mice (genotype by performance: $F_{(1,16)}=4.63 ; p=0.04$; $\left.\mathrm{CHT}^{+/+}: t_{(8)}=2.35 ; p=0.04 ; \mathrm{CHT}^{+/-}: t_{(8)}=0.87 ; p=0.83\right)$.

Concerning the CHT densities in the LP2 fraction, attentional performance preserved the significant difference between the strains observed in nonperforming animals, except for both parietal cortices. Analysis of the densities in the LP2 fraction from the right frontal cortex data confirmed that intracellular $\mathrm{CHT}$ levels in performing animals were lower than in nonperforming mice (main effect of performance: $F_{(1,14)}=13.43 ; p=0.003$ ) but did not differ between the genotypes (no genotype-by-task interaction: $F_{(1,14)}=2.98 ; p=0.11$; Fig. $\left.4 d\right)$. In performing mice, the $\mathrm{LP} 1 / \mathrm{LP} 2$ ratio in right prefrontal cortex was 0.76 in $\mathrm{CHT}^{+/+}$ mice and 0.60 in $\mathrm{CHT}^{+/-}$mice (nonperforming: wild-type, 0.26; $\mathrm{CHT}^{+/-}, 0.46$ ). Thus, compared with the effects of BF-stim, attentional performance was less effective in redistributing $\mathrm{CHTs}$ to plasma membrane-enriched fractions.

To illustrate further the relative changes in the distribution of CHTs when comparing nonperforming and performing wildtype and heterozygous mice, we calculated the proportion of CHTs in the LP1 fraction (LP1/LP2 + LP2) for each animal and region, and expressed these ratios in performing animals as a percentage of the ratios obtained from nonperforming animals (Fig. 4e). This measure illustrates that, in wild-type animals, attentional performance increased the relative proportion of CHTs in synaptosomal plasma membranes from right frontal cortex. No such increase was observed in $\mathrm{CHT}^{+/-}$animals.

Significant correlations were found between $\mathrm{CHT}$ densities in both (synaptosomal plasma membrane-enriched) LP1 and (vesicular membrane-enriched) LP2 right frontal fractions and $\mathrm{SAT}_{500}$ scores from the first task block (LP1: $r=0.71 ; p=0.020$; LP2: $r=0.72 ; p=0.017$; Fig. $4 f$ ). Moreover, CHT densities in the two fractions were significantly correlated (Pearson's $r=0.84$; $p=0.004$ ). As will be discussed below, these correlations reflect the disruption of performance by the distractor and the incomplete recovery from the distractor in both groups of animals, and they are consistent with the conclusion that intracellular CHT density is the primary predictor of stimulation- or performanceinduced increases in CHT density in synaptosomal plasma membrane and thus of attentional performance.

\section{Discussion}

Our experiments investigated the impact of CHT heterozygosity on the capacity of the BF cholinergic projections to the cortex to support high levels of cholinergic neurotransmission in vivo, and on attentional performance that is mediated by, and requires, cholinergic activity. The following main findings were obtained. (1) Baseline measures of cholinergic neurotransmission and evoked ACh release, as well as of choline clearance capacity, were unaffected by CHT heterozygosity. At baseline, the density of CHTs in synaptosomal plasma membrane did not differ between wild-type and $\mathrm{CHT}^{+/-}$mice, accounting for comparable levels of basal and evoked ACh release, and choline clearance. (2) In $\mathrm{CHT}^{+/-}$mice, stimulation of cholinergic neurons resulted in a decreased capacity of cholinergic neurons to release ACh and to clear choline. In wild-type mice, such stimulation increased the mobilization of CHTs as indicated by an increase in CHT density in synaptosomal plasma membrane and a decrease in intracellular CHT density. In $\mathrm{CHT}^{+/-}$mice, such mobilization was atten- 

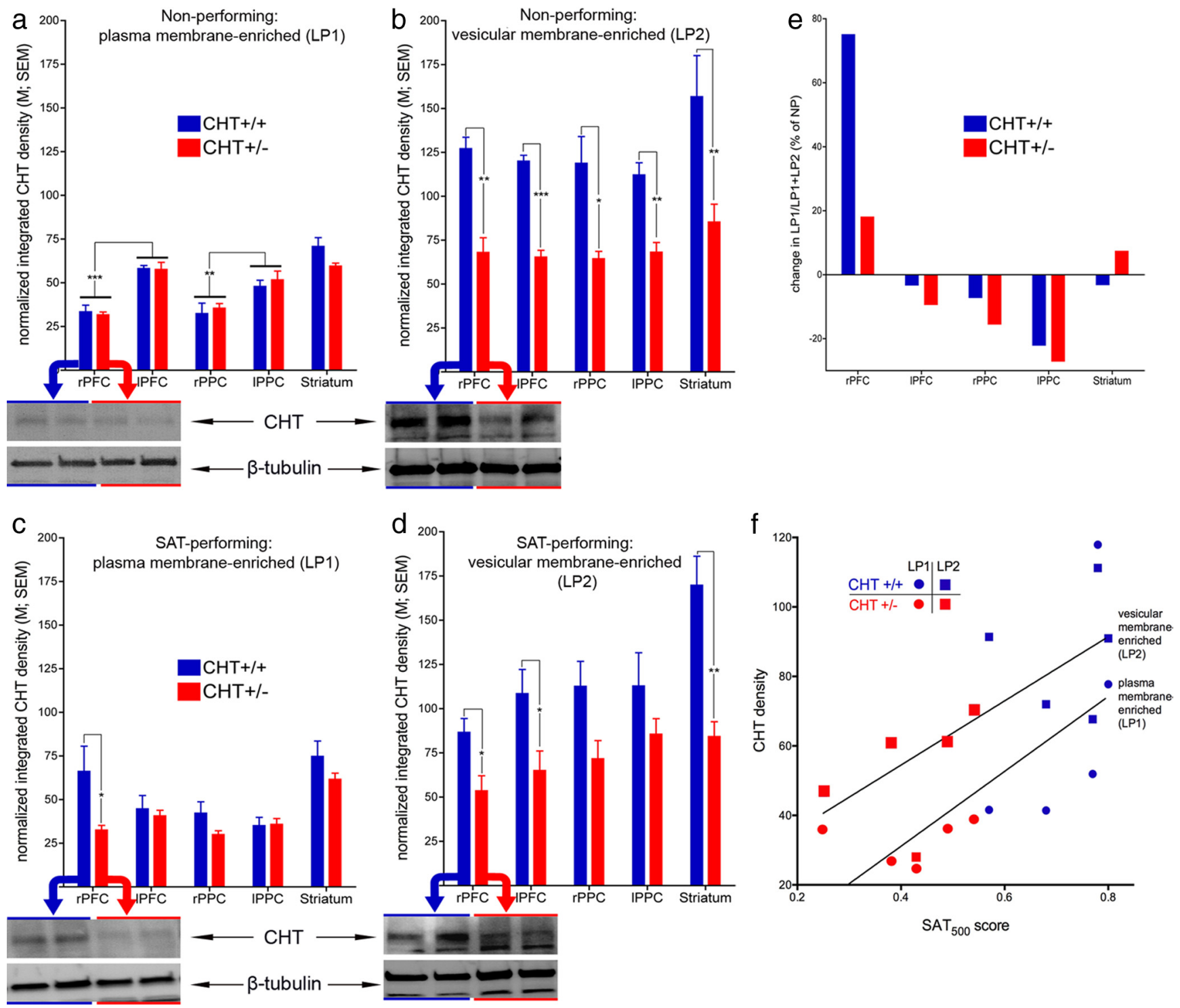

Figure 4. Subcellular CHT distribution following completion of the attentional performance session $\left.\mathrm{CHT}^{+/+}: n=10 ; \mathrm{CH}^{+/-}: n=10\right) . \boldsymbol{a}, \boldsymbol{b}$, Nonperforming animals were handled daily and placed daily into the operant chambers, with houselights turned on, similar to attentional task-performing animals, but the task was never activated. $\boldsymbol{a}, \mathrm{LP1}$ CHT densities did not differ between the genotypes. In nonperforming mice, the LP1 fractions from cortical regions of the left hemisphere contained higher CHT densities than those from the right hemisphere $(\boldsymbol{a})$. $\boldsymbol{b}$, The greater proportion of CHTs was located in the intracellular LP2 fraction (two immunoblots per genotype from right frontal cortex are shown below the bar graphs). c, Following attentional performance, LP1 CHT densities in the right frontal cortex differed between the genotypes, reflecting that attentional performance increased LP1 density in wild-type mice but not CHT ${ }^{+/-}$mice. $\boldsymbol{c}, \boldsymbol{d}$, The performanceinduced increase in CHTs in the plasma membrane (c) did not abolish the larger density of CHTs in the vesicular membrane-enriched LP2 fraction (d; see Results for omnibus ANOVAs; ${ }^{*} p<0.05$; $\left.{ }^{* *} p<0.01 ;{ }^{* *} p<0.001\right)$. To illustrate the magnitude and right frontal selectivity of the attentional performance-induced redistribution of $\mathrm{CHTs}$, $\boldsymbol{e}$ depicts the performance-induced percentage of the relative proportion of CHTs in the LP1 fraction (these are between-subject comparisons and thus are limited to comparing means). $\boldsymbol{f}$, Because tissue data from two mice needed to be pooled for immunoblotting, the corresponding performance data likewise needed to be averaged. Nonetheless, significant positive correlations were found between the attentional performance during block 1 (before the performance-disrupting effects of the distractor) and both LP1 and LP2 densities from the right frontal cortex (f; see Results and Discussion).

uated. At 90 min after stimulation, CHT densities and choline clearance returned to prestimulation levels. However, evoked $\mathrm{ACh}$ release remained attenuated in $\mathrm{CHT}^{+1-}$ mice. (3) Compared with wild-type mice, sustained attention performance was impaired in $\mathrm{CHT}^{+/-}$mice. In wild-type mice, attentional performance increased the density of CHTs in the synaptosomal membrane in the right frontal cortex but not in left cortices and posterior right cortices. Similar to the effects of BF-stim, attentional performance-induced increase in CHT density in synaptosomal plasma membranes was attenuated in CHT heterozygous mice. Attentional performance was significantly correlated with $\mathrm{CHT}$ densities in right frontal synaptosomal plasma membraneenriched and vesicular membrane-enriched fractions.
Developmental plasticity, specifically with respect to postsynaptic mechanisms, may have moderated the consequences of CHT heterozygosity. However, such plasticity likely also occurs in humans expressing a subcapacity variant of the CHT and in patients with other genetic alterations in cholinergic signaling pathways. The current evidence from $\mathrm{CHT}^{+/-}$mice and the findings from humans expressing the I89V variant of the CHT (Hahn et al., 2008; English et al., 2009; Demeter et al., 2010) both indicate that the constitutive loss of CHT function is sufficient to generate impairments in attention.

The present focus on effects on attentional performance and, specifically, the use of the SAT is based on the substantial amount of available evidence indicating the necessity of cortical cholin- 
ergic neurotransmission for SAT performance (McGaughy et al., 1996) and that different aspects of performance are mediated by dissociable components of cholinergic neurotransmission in the cortex (Parikh et al., 2007; Hasselmo and Sarter, 2011). CHT heterozygosity likely limits the capacity of, specifically, the tonic component of cholinergic neurotransmission, as opposed to cueevoked, second-based transients, in part because the former is elevated during dSAT performance and thus requires sustained elevation of ACh synthesis and release (St Peters et al., 2011a). The present evidence corroborates the hypothesis that the necessity for elevated cholinergic activity to support sustained attentional performance is limited to the right hemisphere (see also Martinez and Sarter, 2004; Apparsundaram et al., 2005). Evidence from humans performing the SAT and dSAT likewise indicates a right-hemispheric specialization of such performance (Demeter et al., 2011).

Stimulation-induced increases in LP1 fractions were accounted for by decreases in the LP2 fraction. This observation is consistent with the hypothesis that, upon depolarization, CHTs are translocated into plasma membrane (Ferguson and Blakely, 2004) and, as indicated by the restoration at $90 \mathrm{~min}$ after BF-stim, effectively recycled thereafter. Furthermore, even the potent effects of BF-stim did not increase the redistribution of CHTs to the plasma membrane beyond a LP1/LP2 ratio of $1: 1$ in $\mathrm{CHT}^{+/+}$ mice. Thus, behavioral/cognitive activation of the cholinergic system appears to be generally constrained by this ratio.

The lower LP2 CHT density in mutant mice predicted the limited stimulation-induced translocation of CHTs into the plasma membrane. A substantial proportion of intracellular CHTs may not be available for neuronal activity-induced outward movement or may require long-term plasticity to establish a larger pool of transporters that can be mobilized. Such a possibility will be an important direction for future studies and may have relevance for therapeutic development. Although it is difficult to estimate the intracellular proportion of $\mathrm{CHT}$ s that is not available for this type of translocation, in part because endocytosis is not impeded, and may be accelerated, during the first $10 \mathrm{~min}$ after BF-stim, this pool may be as large as $50 \%$. CHTs that are not translocated into the synaptic plasma membrane by BF-stim may be situated in nonvesicular endosomal compartments and thus subject to translocation mechanisms that are unrelated to depolarization (Ribeiro et al., 2006), although EM analyses do not point to this localization as a major depot (Ferguson et al., 2003; Holmstrand et al., 2010). Studies of releasable pools of vesicles at many synapses point to a large number of synaptic vesicles that fail to mobilize, even with strong stimuli (Rizzoli and Betz, 2005). Clearly, a better understanding of the regulation of these mechanisms will be critical to understand how cholinergic neurotransmission is influenced by other neuronal systems and signaling pathways.

At 90 min after BF-stim, CHT distribution in both genotypes had returned to levels seen in nonstimulated animals. Likewise, choline clearance had completely recovered. However, in $\mathrm{CHT}^{+/-}$mice, evoked ACh release remained attenuated. As it seems unlikely that intracellular ACh synthesis did not return to baseline levels after such a long period, CHT endocytosis in $\mathrm{CHT}^{+/-}$mice may also contribute to intracellular regulation of $\mathrm{ACh}$ release mechanisms. The impact of $\mathrm{CHT}$ heterozygosity may not be fully described merely by lower levels of CHTs in intracellular compartments.

In wild-type animals, the effect of attentional performance on CHT density in plasma membranes was limited to the right frontal cortex. The regional selectivity of this upregulation corre- sponds with activation patterns seen in humans performing a version of the same attention task that was adapted and revalidated for use in humans (Demeter et al., 2011). Such increases in right frontal cholinergic neurotransmission may modulate cortical circuitry in response to performance challenges, resulting in the enhancement of cue detection mechanisms and perhaps also the filtering of distractors (Hasselmo and Sarter, 2011; St Peters et al., 2011a). As indicated by the absence of CHT density changes in $\mathrm{CHT}^{+/-}$mice, they were not able to recruit or enhance such "top-down" processes. Accordingly, their postdistractor performance did not recover from levels seen during the distractor.

LP1 CHT densities were correlated with performance during the first, predistractor block of trials. In mice that performed better from the outset, there were more CHTs in the right frontal LP2 fraction and thus more CHTs may have been available for translocation into the membrane. This hypothesis also explains the positive correlation between performance and LP2 CHT density, and between CHT densities in both fractions.

In the current experiment, the distractor suppressed the performance of all animals to chance levels, with incomplete and variable recovery of performance after distractor termination. Using a more moderately effective manipulation to challenge attentional performance and underlying cholinergic capacity may allow the demonstration of superior performance of wild-type mice during the distractor and the performance benefits that result from $\mathrm{CHT}$ mobilization in wild-type animals.

Our work extends to a cognitive dimension the inability of $\mathrm{CHT}^{+/-}$animals to sustain prolonged treadmill activity or to respond to the challenge of restoring heart rate after exercise (Bazalakova et al., 2007; English et al., 2010). Furthermore, these animals' attentional performance is impaired, and the evidence supports the hypothesis that this impairment is due to limited increases in the number of CHTs in the right frontal cortex. $\mathrm{CHT}^{+/-}$mice may serve as an animal model for investigating two key issues.

Humans that carry one or two copies of a CHT coding variant with reduced activity (Okuda et al., 2002) are at increased risk for ADHD (English et al., 2009). Furthermore, we have recently determined that openly recruited humans expressing the lowfunctioning variant (IIe89Val) exhibit heightened distractibility in situations demanding sustained attention (Demeter et al., 2010). Our studies indicate that the $\mathrm{CHT}^{+/-}$mice will assist in further specifying the impact of constitutive loss of CHT capacity by other, including monoaminergic, signaling pathways. Although the role of CHT dysregulation in brain pathological processes is not well understood, $\mathrm{CHT}^{+/-}$mice should may also be useful in investigating the mechanisms that render cholinergic neurons vulnerable to neurodegenerative processes, or the cognitive changes that can appear in advance of pathology, and thus for the integrity and functions of cortical circuitry modulated by ACh, including the neurovascular interface (Yamada et al., 2001; Van Beek and Claassen, 2011). Consistent with this idea, Zurkovsky et al. (2013) recently demonstrated that the cognitive deficits displayed by $\mathrm{CHT}^{+/-}$mice are exacerbated by loss of nigrostriatal dopaminergic neurons.

\section{References}

Apparsundaram S, Martinez V, Parikh V, Kozak R, Sarter M (2005) Increased capacity and density of choline transporters situated in synaptic membranes of the right medial prefrontal cortex of attentional taskperforming rats. J Neurosci 25:3851-3856. CrossRef Medline

Auld DS, Kornecook TJ, Bastianetto S, Quirion R (2002) Alzheimer's disease and the basal forebrain cholinergic system: relations to beta-amyloid 
peptides, cognition, and treatment strategies. Prog Neurobiol 68: 209-245. CrossRef Medline

Bales KR, Tzavara ET, Wu S, Wade MR, Bymaster FP, Paul SM, Nomikos GG (2006) Cholinergic dysfunction in a mouse model of Alzheimer disease is reversed by an anti-A $\beta$ antibody. J Clin Invest 116:825-832. CrossRef Medline

Barwick KE, Wright J, Al-Turki S, McEntagart MM, Nair A, Chioza B, AlMemar A, Modarres H, Reilly MM, Dick KJ, Ruggiero AM, Blakely RD, Hurles ME, Crosby AH (2012) Defective presynaptic choline transport underlies hereditary motor neuropathy. Am J Hum Genet 91:1103-1107. CrossRef Medline

Bazalakova MH, Wright J, Schneble EJ, McDonald MP, Heilman CJ, Levey AI, Blakely RD (2007) Deficits in acetylcholine homeostasis, receptors and behaviors in choline transporter heterozygous mice. Genes Brain Behav 6:411-424. CrossRef Medline

Boix-Trelis N, Vale-Martínez A, Guillazo-Blanch G, Costa-Miserachs D, Martí-Nicolovius M (2006) Effects of nucleus basalis magnocellularis stimulation on a socially transmitted food preference and c-Fos expression. Learn Mem 13:783-793. CrossRef Medline

Demeter E, Sarter M, Lustig C (2008) Rats and humans paying attention: cross-species task development for translational research. Neuropsychology 22:787-799. CrossRef Medline

Demeter E, Sabhapathy S, Blakely RD, Sarter M, Lustig C (2010) Reduced attentional control in humans expressing the gene for a subcapacity version of the choline transporter. Paper presented at 17th Annual Meeting of the Cognitive Neuroscience Society, Montreal, QC, Canada, March.

Demeter E, Hernandez-Garcia L, Sarter M, Lustig C (2011) Challenges to attention: a continuous arterial spin labeling (ASL) study of the effects of distraction on sustained attention. Neuroimage 54:1518-1529. CrossRef Medline

Edeline JM, Hars B, Maho C, Hennevin E (1994) Transient and prolonged facilitation of tone-evoked responses induced by basal forebrain stimulations in the rat auditory cortex. Exp Brain Res 97:373-386. Medline

English BA, Hahn MK, Gizer IR, Mazei-Robison M, Steele A, Kurnik DM, Stein MA, Waldman ID, Blakely RD (2009) Choline transporter gene variation is associated with attention-deficit hyperactivity disorder. J Neurodev Disord 1:252-263. CrossRef Medline

English BA, Appalsamy M, Diedrich A, Ruggiero AM, Lund D, Wright J, Keller NR, Louderback KM, Robertson D, Blakely RD (2010) Tachycardia, reduced vagal capacity, and age-dependent ventricular dysfunction arising from diminished expression of the presynaptic choline transporter. Am J Physiol Heart Circ Physiol 299:H799-H810. CrossRef Medline

Ferguson SM, Blakely RD (2004) The choline transporter resurfaces: new roles for synaptic vesicles? Mol Interv 4:22-37. CrossRef Medline

Ferguson SM, Savchenko V, Apparsundaram S, Zwick M, Wright J, Heilman CJ, Yi H, Levey AI, Blakely RD (2003) Vesicular localization and activity-dependent trafficking of presynaptic choline transporters. J Neurosci 23:9697-9709. Medline

Ferguson SM, Bazalakova M, Savchenko V, Tapia JC, Wright J, Blakely RD (2004) Lethal impairment of cholinergic neurotransmission in hemicholinium-3-sensitive choline transporter knockout mice. Proc Natl Acad Sci U S A 101:8762-8767. CrossRef Medline

Gates J Jr, Ferguson SM, Blakely RD, Apparsundaram S (2004) Regulation of choline transporter surface expression and phosphorylation by protein kinase $\mathrm{C}$ and protein phosphatase 1/2A. J Pharmacol Exp Ther 310:536545. CrossRef Medline

Goard M, Dan Y (2009) Basal forebrain activation enhances cortical coding of natural scenes. Nat Neurosci 12:1444-1449. CrossRef Medline

Greenwald AG, Gonzalez R, Harris RJ, Guthrie D (1996) Effect sizes and p values: what should be reported and what should be replicated? Psychophysiology 33:175-183. CrossRef Medline

Hahn MK, Blackford JU, Haman K, Mazei-Robison M, English BA, Prasad HC, Steele A, Hazelwood L, Fentress HM, Myers R, Blakely RD. SandersBush E, Shelton R (2008) Multivariate permutation analysis associates multiple polymorphisms with subphenotypes of major depression. Genes Brain Behav 7:487-495. CrossRef Medline

Hasselmo ME, Sarter M (2011) Modes and models of forebrain cholinergic neuromodulation of cognition. Neuropsychopharmacol Rev 36:52-73. CrossRef

Holmstrand EC, Asafu-Adjei J, Sampson AR, Blakely RD, Sesack SR (2010)
Ultrastructural localization of high-affinity choline transporter in the rat anteroventral thalamus and ventral tegmental area: differences in axon morphology and transporter distribution. J Comp Neurol 518:19081924. CrossRef Medline

Kozak R, Martinez V, Young D, Brown H, Bruno JP, Sarter M (2007) Toward a neuro-cognitive animal model of the cognitive symptoms of schizophrenia: disruption of cortical cholinergic neurotransmission following repeated amphetamine exposure in attentional task-performing, but not non-performing, rats. Neuropsychopharmacology 32:20742086. CrossRef Medline

Kus L, Borys E, Ping Chu Y, Ferguson SM, Blakely RD, Emborg ME, Kordower JH, Levey AI, Mufson EJ (2003) Distribution of high affinity choline transporter immunoreactivity in the primate central nervous system. J Comp Neurol 463:341-357. CrossRef Medline

Manaker S, Wieczorek CM, Rainbow TC (1986) Identification of sodiumdependent, high-affinity choline uptake sites in rat brain with [3H] hemicholinium-3. J Neurochem 46:483-488. CrossRef Medline

Martinez V, Sarter M (2004) Lateralized attentional functions of cortical cholinergic inputs. Behav Neurosci 118:984-991. CrossRef Medline

McGaughy J, Kaiser T, Sarter M (1996) Behavioral vigilance following infusions of 192 IgG-saporin into the basal forebrain: selectivity of the behavioral impairment and relation to cortical AChE-positive fiber density. Behav Neurosci 110:247-265. Medline

McLin DE 3rd, Miasnikov AA, Weinberger NM (2002) Induction of behavioral associative memory by stimulation of the nucleus basalis. Proc Nat Acad Sci U S A 99:4002-4007. CrossRef Medline

Mesulam M (2004) The cholinergic lesion of Alzheimer's disease: pivotal factor or side show? Learn Mem 11:43-49. CrossRef Medline

Misawa H, Nakata K, Matsuura J, Nagao M, Okuda T, Haga T (2001) Distribution of the high-affinity choline transporter in the central nervous system of the rat. Neuroscience 105:87-98. CrossRef Medline

Nuechterlein KH, Luck SJ, Lustig C, Sarter M (2009) CNTRICS final task selection: control of attention. Schizophr Bull 35:182-196. CrossRef Medline

Okuda T, Okamura M, Kaitsuka C, Haga T, Gurwitz D (2002) Single nucleotide polymorphism of the human high affinity choline transporter alters transport rate. J Biol Chem 277:45315-45322. CrossRef Medline

Parikh V, Sarter M (2006) Cortical choline transporter function measured in vivo using choline-sensitive microelectrodes: clearance of endogenous and exogenous choline and effects of removal of cholinergic terminals. J Neurochem 97:488-503. CrossRef Medline

Parikh V, Pomerleau F, Huettl P, Gerhardt GA, Sarter M, Bruno JP (2004) Rapid assessment of in vivo cholinergic transmission by amperometric detection of changes in extracellular choline levels. Eur J Neurosci 20: 1545-1554. CrossRef Medline

Parikh V, Apparsundaram S, Kozak R, Richards JB, Sarter M (2006) Reduced expression and capacity of the striatal high-affinity choline transporter in hyperdopaminergic mice. Neuroscience 141:379-389. CrossRef Medline

Parikh V, Kozak R, Martinez V, Sarter M (2007) Prefrontal acetylcholine release controls cue detection on multiple timescales. Neuron 56:141154. CrossRef Medline

Parikh V, Man K, Decker MW, Sarter M (2008) Glutamatergic contributions to nicotinic acetylcholine receptor agonist-evoked cholinergic transients in the prefrontal cortex. J Neurosci 28:3769-3780. CrossRef Medline

Parikh V, Ji J, Decker MW, Sarter M (2010) Prefrontal $\beta 2$ subunitcontaining and $\alpha 7$ nicotinic acetylcholine receptors differentially control glutamatergic and cholinergic signaling. J Neurosci 30:3518-3530. CrossRef Medline

Pinthong M, Black SA, Ribeiro FM, Pholpramool C, Ferguson SS, Rylett RJ (2008) Activity and subcellular trafficking of the sodium-coupled choline transporter $\mathrm{CHT}$ is regulated acutely by peroxynitrite. Mol Pharmacol 73:801-812. CrossRef Medline

Ribeiro FM, Alves-Silva J, Volknandt W, Martins-Silva C, Mahmud H, Wilhelm A, Gomez MV, Rylett RJ, Ferguson SS, Prado VF, Prado MA (2003) The hemicholinium-3 sensitive high affinity choline transporter is internalized by clathrin-mediated endocytosis and is present in endosomes and synaptic vesicles. J Neurochem 87:136-146. CrossRef Medline

Ribeiro FM, Black SA, Cregan SP, Prado VF, Prado MA, Rylett RJ, Ferguson SS (2005) Constitutive high-affinity choline transporter endocytosis is 
determined by a carboxyl-terminal tail dileucine motif. J Neurochem 94:86-96. CrossRef Medline

Ribeiro FM, Black SA, Prado VF, Rylett RJ, Ferguson SS, Prado MA (2006) The "ins" and "outs" of the high-affinity choline transporter CHT1. J Neurochem 97:1-12. CrossRef Medline

Rizzoli SO, Betz WJ (2005) Synaptic vesicle pools. Nat Rev Neurosci 6:57-69. CrossRef Medline

Robinson TE, Green DJ (1980) Effects of hemicholinium-3 and choline on hippocampal electrical activity during immobility vs movement. Electroencephalogr Clin Neurophysiol 50:314-323. CrossRef Medline

Ruggiero AM, Wright J, Ferguson SM, Lewis M, Emerson KS, Iwamoto H, Ivy MT, Holmstrand EC, Ennis EA, Weaver CD, Blakely RD (2012) A nonoisotopic assay for the presynaptic choline transporter reveals capacity for allosteric modulation of choline uptake. ACS Chem Neurosci 3:767-781. CrossRef Medline

Saltarelli MD, Lowenstein PR, Coyle JT (1987) Rapid in vitro modulation of $[3 \mathrm{H}]$ hemicholinium-3 binding sites in rat striatal slices. Eur J Pharmacol 135:35-40. CrossRef Medline

Saltarelli MD, Yamada K, Coyle JT (1990) Phospholipase A2 and 3Hhemicholinium- 3 binding sites in rat brain: a potential second-messenger role for fatty acids in the regulation of high-affinity choline uptake. J Neurosci 10:62-72. Medline

Sarter M, Parikh V (2005) Choline transporters, cholinergic transmission and cognition. Nat Rev Neurosci 6:48-56. CrossRef Medline

Sarter M, Gehring WJ, Kozak R (2006) More attention must be paid: the neurobiology of attentional effort. Brain Res Rev 51:145-160. CrossRef Medline

Sarter M, Lustig C, Taylor SF (2012) Cholinergic contributions to the cognitive symptoms of schizophrenia and the viability of cholinergic treatments. Neuropharmacology 62:1544-1553. CrossRef Medline
Simon JR, Atweh S, Kuhar MJ (1976) Sodium-dependent high affinity choline uptake: a regulatory step in the synthesis of acetylcholine. J Neurochem 26:909-922. CrossRef Medline

St Peters M, Demeter E, Lustig C, Bruno JP, Sarter M (2011a) Enhanced control of attention by stimulating mesolimbic-corticopetal cholinergic circuitry. J Neurosci 31:9760-9771. CrossRef Medline

St Peters M, Cherian AK, Bradshaw M, Sarter M (2011b) Sustained attention in mice: expanding the translational utility of the SAT by incorporating the Michigan Controlled Access Response Port (MICARP). Behav Brain Res 225:574-583. CrossRef Medline

Van Beek AH, Claassen JA (2011) The cerebrovascular role of the cholinergic neural system in Alzheimer's disease. Behav Brain Res 221:537542. CrossRef Medline

Wang B, Yang L, Wang Z, Zheng H (2007) Amyolid precursor protein mediates presynaptic localization and activity of the high-affinity choline transporter. Proc Natl Acad Sci U S A 104:14140-14145. CrossRef Medline

Yamada M, Lamping KG, Duttaroy A, Zhang W, Cui Y, Bymaster FP, McKinzie DL, Felder CC, Deng CX, Faraci FM, Wess J (2001) Cholinergic dilation of cerebral blood vessels is abolished in M(5) muscarinic acetylcholine receptor knockout mice. Proc Natl Acad Sci U S A 98:14096-14101. CrossRef Medline

Yamamura HI, Snyder SH (1972) Choline: high-affinity uptake by rat brain synaptosomes. Science 178:626-628. CrossRef Medline

Zurkovsky L, Bychkov E, Tsakem EL, Siedlecki C, Blakely RD, Gurevich EV (2013) Cognitive effects of dopamine depletion in the context of diminished acetylcholine signaling capacity. Dis Model Mech 6:171-183. CrossRef Medline 